\title{
Aproximação entre Agamben e Comitê Invisível ${ }^{1}$
}

Diego Guimarães ${ }^{2}$

Resumo: Este artigo tem como objetivo aproximar a obra de Giorgio Agamben da obra do Comitê Invisível, com o intuito de destacar, em ambos, características vinculadas à resistência anárquica. Primeiro, recapitula-se a relação do filósofo italiano com a revista Tiqqun, publicada pelo Partido Imaginário, grupo do qual se derivou o Comitê Invisível. Na sequência, avança-se na aproximação em questão neste artigo, passando por três obras publicadas pelo grupo francês: $A$ insurreição que vem (2013), Aos nossos amigos: crise e insurreição (2016) e Motim e destituição agora (2017): na primeira, destacamse os conceitos de insurreição e que vem; na segunda obra, destaca-se o conceito de potência destituinte; na terceira, aprofunda-se na potência destituinte e no conceito de agora, que por sua vez se relaciona com o conceito de tempo-do-agora trabalhado por Agamben. Por fim, tem-se que o conceito de potência destituinte figura nas obras do Comitê Invisível de maneira semelhante à que figura nas obras de Agamben, e também que o agora e o tempo-de-agora, em relação com o uso e com a forma-de-vida, mostram-se cruciais para a compreensão da potência destituinte tanto em Agamben quanto no Comitê Invisível. Ao mesmo tempo, tal aproximação aponta para uma relação da obra do filósofo italiano com a tradição de pensamento anárquico, conferindo à obra agambeniana uma perspectiva prática de resistência ao governo da vida.

Palavras-chave: Agamben - Comitê Invisível - Destituição - Insurreição - Resistência

\section{Approach between Agamben and Invisible Committee}

\begin{abstract}
This article aims to bring the work of Giorgio Agamben closer to the work of the Invisible Committee, in order to highlight, in both, characteristics linked to anarchic resistance. First, the relationship of the Italian philosopher with Tiqqun magazine, published by the Imaginary Party, from which the Invisible Committee was derived, is reviewed. Following, the approach in question in this article is advanced, passing through three works published by the French group: The comming insurrection (2013), To our friends: crisis and insurrection (2016) and Riot and destitution now (2017): in the first, they highlight up the concepts of insurrection and what comes; in the second work, the concept of destituent power stands out; in the third, it delves into the destituent power and the concept of now, which in turn relates to Agamben's concept of time-of-now. Finally, the concept of destituent power appears in the works of the Invisible Committee in a similar way to that in Agamben's works, and also that the now and the time-of-now, in relation to the use and form-of-life, are crucial for understanding the destituent power in both Agamben and the Invisible Committee. At the same time, such an approach points to a relationship between the work of the Italian philosopher and the tradition of anarchic thinking, giving the Agambenian work a practical perspective of resistance to the rule of life.
\end{abstract}

Keywords: Agamben - Invisible Committee - Destitution - Insurrection - Resistance

\footnotetext{
${ }^{1}$ Este artigo deriva-se de parte da minha tese de doutorado intitulada O gesto de anarquia a partir da obra de Giorgio Agamben (UFPB, 2019).

2 Doutor em filosofia pela Universidade Federal da Paraíba (UFPB). Professor da Secretaria da Educação e da Ciência e Tecnologia da Paraíba (SEECT-PB). E-mail: diegoguimafil@gmail.com.
} 
Relacionar a obra de Agamben com o anarquismo é mais uma proposta deste artigo do que uma relação explícita daquele filósofo com a tradição de pensamento anárquico, ou seja, o anarquismo não é um tema sobre o qual Agamben tenha se debruçado de maneira demorada. Mesmo assim, há em sua obra momentos em que ele trata explicitamente da anarquia e do anarquismo, como em: O tempo que resta (2000), na qual passa pelo tema da insurreição; em $O$ uso dos corpos (2014), que versa sobre o conceito de potência destituinte e aborda uma potência anárquica; Creazione e anarchia (2017b), composta por ensaios que envolvem, de maneira peculiar e indireta, a anarquia e o anarquismo; bem como aquelas obras em que Agamben aborda o Partido Imaginário e o conceito de bloom, às quais apontarei adiante.

Uma característica marcante do pensamento anárquico é a resistência ao governo. Isso não significa que onde há resistência a governo há um pensamento estritamente anarquista, mas que, no mínimo, é possível lidar com tal resistência de uma perspectiva anárquica. A anarquia caracteriza-se por ser uma situação de não-governo, uma ausência de governo sobre as pessoas e sobre as relações entre as pessoas. $\mathrm{O}$ anarquismo, ao adotar a anarquia como ponto de partida, dedica-se em seu corpo teórico e prático, sobretudo, a manter as situações e condições de não-governo, dedicando-se a resistir a toda forma de captura e condução da vida.

A obra de Agamben é caracteristicamente vinculada a uma resistência ao governo da vida na medida em que ela se dedica, sobretudo a partir da tetralogia Homo Sacer, a explicitar a captura da vida por dispositivos ${ }^{3}$ de governo (que resulta na vida nua) e a destacar a possibilidade de uma forma-de-vida ao invés de uma vida cindida das suas formas. O conceito de forma-de-vida surge em Agamben como uma resposta àquele de vida nua, opondo-se a esta. Enquanto a vida nua é a vida capturada, cujas formas são tomadas como propriedade, e, assim, mediadas e guiadas por dispositivos de governo, a forma-de-vida é caracterizada como uso, uma imanência entre forma e vida, de modo que aqui a vida e a forma não são tomadas como propriedade, mas como algo disponível para um uso sempre novo. Através dos conceitos de inoperosidade e de potência destituinte, como veremos à frente, Agamben destaca uma via para intensificar a forma-de-vida e resistir à captura e ao governo da vida. É através dessas características de resistência que faremos a aproximação entre a obra do filósofo italiano e o Comitê Invisível.

Antes de analisarmos a relação entre a obra de Agamben e o Comitê Invisível, faz-se necessário abordar a relação do filósofo italiano com as publicações do Partido Imaginário, do qual se derivou o Comitê Invisível. O Partido Imaginário é um grupo francês que manteve uma revista intitulada Tiqqun, publicada entre 1999 e 2001. De modo geral, seus ensaios versam sobre: 1) uma crítica à mobilização e mediação do vivido, que são características da sociedade do espetáculo (na qual as relações sociais são mediadas por imagens); 2) vias para desmobilização dos viventes, de modo a fortalecer e intensificar a imediaticidade da vida com as formas em que ela se dá, ou seja, o Partido Imaginário debruça-se sobre a vida vivida sem mediação de governo. Dois ensaios da revista Tiqqun, o Théorie du bloom (1999) e o Introduction à la guerre civile (2001), evidenciam forte influência da obra do filósofo Giorgio Agamben, seja pelo uso de conceitos importantes para o filósofo italiano, tais como os conceitos de vida

${ }^{3}$ Agamben chama de dispositivo "qualquer coisa que tenha de algum modo a capacidade de capturar, orientar, determinar, interceptar, modelar, controlar e assegurar os gestos, as condutas, as opiniões e os discursos dos seres viventes" (AGAMBEN, O que é um dispositivo?, p. 40). 
nua, forma-de-vida e relação de exceção ${ }^{4}$, seja por referências diretas a Agamben; este, por sua vez, aborda o grupo Partido Imaginário (principalmente através do conceito de bloom) em obras como: A comunidade que vem (2013), O que é um dispositivo? (2009), O uso dos corpos (2017b) e Autoritratto nello studio (2017a).

O conceito de bloom ${ }^{5}$, desenvolvido pelo Partido Imaginário em Théorie du bloom (1999), indica uma condição da pessoa que se encontra sem identidade e sem conteúdo; para ser mais preciso, seria o caso em que ela está quase totalmente sem identidade e experiência, possuindo-as apenas num estágio larval, escasso de experiências e raízes. Em tal condição, uma pessoa não possui nada de significativo que a determine enquanto singularidade.

O bloom nomeia portanto a nudez nova e sem idade, a nudez propriamente humana que desaparece sob cada atributo e ainda a porta, que precede qualquer forma e torna isso possível. O Bloom é um nada mascarado. (...) o homem sem qualidade não é uma certa qualidade do homem, mas ao contrário $o$ homem enquanto homem. A falta de identidade própria, a abstração de todo meio substancial, a ausência de determinação "natural", longe de atribuí-la a qualquer particularidade, designam-na como a realização da essência humana genérica, que é precisamente a privação de essência, pura exposição e pura disponibilidade. ${ }^{6}$

O bloom não pertence ou participa de nada além de uma essência genérica: pessoa enquanto pessoa; pessoa que, por estar esvaziada de toda qualidade, de nenhuma maneira importa. De modo que à condição de bloom pertence a característica de qualquer, no sentido de não importar qual, de nenbuma maneira importar qual e de ser indiferente qual. No entanto, há um outro conceito de qualquer, um que interessa ao Partido Imaginário para pensar como sair da condição de bloom, cujo sentido tem por referência a obra $A$ comunidade que vem, de Giorgio Agamben: "Qualquer é a coisa com todas as suas propriedades, nenhuma das quais constitui, porém, diferença"

Agamben, por sua vez, aborda o conceito de bloom no posfácio da obra $A$ comunidade que vem:

O próprio de tal tempo - do nosso tempo - é que, em um certo momento, todos - todos os povos e todos os homens da terra - se encontraram em posição de resto. Isso implica, olhando bem, uma generalização sem precedentes da condição messiânica, na qual o que era, de início, apenas uma hipótese - a ausência de obra, a singularidade qualquer, o bloom - se tornou realidade. ${ }^{8}$

\footnotetext{
4 A exceção dá origem à vida nua: separa a vida em vida natural e vida qualificada, isto é, a vida e as formas em que ela se dá; transforma a vida natural em propriedade, essência e fundamento, separando-a da esfera humana, ou seja, há uma sacralização da vida. Assim, o que era vivido diretamente deixa de sê-lo: a mediação entre forma e vida abre caminho para o governo da vida.

5 O termo bloom tem como referência o personagem Leopold Bloom, do romance Ulysses (1922), de James Joyce. Trata-se de um personagem esvaziado tanto de seu mundo quanto de si mesmo.

${ }^{6}$ PARTI IMAGINAIRE, Théorie du bloom, p. 25; tradução nossa.

${ }^{7}$ AGAMBEN, A comunidade que vem, p. 27.

8 AGAMBEN, A comunidade que vem, p. 102.
} 
Em ambos os sentidos dados para qualquer, tanto no que pertence ao bloom quanto no que se contrapõe a ele, não há uma identidade comum ou um pertencimento a algo partilhado. No caso do sentido de qualquer vinculado ao bloom, a ausência de pertencimento está ligada a um vazio, ele é o mesmo que um vazio de pertencimento. Já no segundo sentido dado a qualquer, não ter uma condição de pertencimento não significa um vazio, mas uma indiferença de pertencimento, de modo que este qualquer compartilharia o próprio pertencimento: a pessoa com todo o seu conteúdo, experiências e qualidades, quaisquer elas sejam.

Ao final do ensaio Introdução à guerra civil (2001), o Partido Imaginário indica um prosseguimento daquela investigação, no âmbito teórico e prático, a partir de uma extensão do grupo, denominado Comitê Invisível:

As declarações precedentes pretendem introduzir a uma época cada vez mais tangivelmente ameaçada pela inundação em massa da realidade. A ética da guerra civil que foi expressa aqui recebeu um dia o nome de "Comitê Invisível". Assina uma fração determinada do Partido Imaginário, seu polo revolucionário-experimental. Através dessas linhas, esperamos frustrar as bobagens mais vulgares que podem ser feitas sobre nossas atividades, como no período que se abre. ${ }^{9}$

Tanto o Partido Imaginário quanto o Comitê Invisível pensam a contemporaneidade a partir de uma perspectiva anárquica, debruçando-se sobre as formas como as pessoas relacionam-se e organizam-se, criticando, nesse percurso, toda forma de governo e defendendo a ausência de governo nas vidas das pessoas e nas relações entre elas. Enquanto o Partido Imaginário tem um ponto de partida mais teórico para os seus ensaios (o que não significa serem desvinculados da prática), o Comitê Invisível parte de experimentos práticos no encontro entre pessoas, para a partir deles ensaiar. O Comitê Invisível debruça-se mais sobre situações práticas, pensando a partir da participação de seus integrantes/colaboradores em diversas manifestações em diferentes países ao longo das últimas duas décadas; estas manifestações permeiam os seus livros quando desenvolvem, com elas, perspectivas para o fortalecimento do que chama, num primeiro momento, de potência, e, num segundo momento, de potência destituinte. Tendo o Partido Imaginário dado ênfase ao conceito de bloom, à forma-de-vida e ao fortalecimento de uma potência a ela atrelada, o Comitê Invisível se ocupará de investigar tal potência a partir de eventos e experimentos práticos (sobretudo com a observação e/ou participação em diversas manifestações ocorridas nas últimas décadas), que resultará, por fim, em uma reflexão e em uma elaboração de um conceito de potência destituinte.

No Comitê Invisível temos uma continuação do pensamento do que o Partido Imaginário chama de fortalecimento da potência ${ }^{10}$ (que tem em sua concepção relação com o conceito de forma-de-vida de Agamben e a problemática que essa envolve), por meio do conceito de potência destituinte (também importante na obra agambeniana). Com esse

\footnotetext{
9 PARTI IMAGINAIRE, Introdução à guerra civil, p. 37; tradução nossa.

$10 \mathrm{O}$ fortalecimento da potência diz respeito a uma intensificação da formas-de-vida, ou seja, a um fortalecimento da relação entre a vida e as formas com que ela se dá.
} 
conceito temos uma via privilegiada de aproximação entre Agamben e o anarquismo a partir do Comitê Invisível.

Uma diferença entre a relação da obra de Agamben com o Partido Imaginário, e a aproximação que faremos entre Agamben e Comitê Invisível, diz respeito ao fato de o filósofo não fazer referência ou citar o Comitê Invisível no interior de suas obras, salvo nos artigos e conferências em que ele fala sobre o episódio conhecido com os nove de Tarnac. Nosso percurso a partir de agora será pautado mais pela apropriação que o grupo faz dos conceitos agambenianos do que por referências do filósofo a ele.

Num caso que ficou conhecido como os nove de Tarnac, um grupo de amigos que moravam juntos foi acusado de terrorismo por sabotagem de uma linha férrea. Dentre as provas mobilizadas contra eles estava a suposta autoria desse livro. As acusações não se sustentaram (... ${ }^{11}$.

O evento conhecido como os nove de Tarnac seguiu-se à publicação de $A$ insurreição que vem (2013) e envolveu um dos editores da revista Tiqqun, do Partido Imaginário, Julian Coupat. No ano de publicação do texto, Coupat e mais oito pessoas foram presas (elas estavam juntas numa cidade chamada Tarnac, por isso a referência no nome como conhecido o acontecimento) e acusadas de terrorismo. No artigo Terrorismo ou tragicomédia (2008), Agamben critica os motivos alegados para a prisão, destacando que o que vai de encontro ao status quo tende a ser visto pelos governos como potencialmente terrorista.

É preciso ter a coragem de dizer com clareza que hoje, em muitos países europeus (particularmente na França e na Itália), introduziram-se leis e medidas de polícia que no passado teriam sido julgadas como bárbaras e antidemocráticas e que não têm nada a invejar daquelas que vigoravam na Itália durante o fascismo. Uma dessas medidas é aquela que autoriza a detenção por uma duração de 96 horas de um grupo de jovens, talvez imprudentes, mas aos quais "não é possível imputar uma ação". Outra medida muito mais grave é a adoção das leis que introduzem delitos de associação, cuja formulação é deixada intencionalmente vaga e que permite classificar como "de fundo" ou com "vocação" terrorista atos políticos que até hoje jamais foram considerados como destinados a produzir terror. ${ }^{12}$

Dando sequência à aproximação entre Agamben e o Comitê Invisível, temos que este grupo tem três livros publicados até o momento: A insurreição que vem (2013), Aos nossos amigos: crise e insurreição (2016) e Motim e destituição agora (2017). Passaremos por essas três obras, aproximando-as de Agamben: na $1^{\mathrm{a}}$ obra, destacam-se os conceitos de insurreição e que vem; na $2^{a}$ obra, destaca-se o conceito de potência destituinte; na $3^{a}$ obra, aprofunda-se na potência destituinte e no conceito de agora, que por sua vez se relaciona com o conceito de tempo-doagora trabalhado por Agamben, entre outras obras, em O tempo que resta (2016).

${ }^{11}$ COMITÊ INVISÍVEL, $A$ insurreição que vem, p. 3.

12 AGAMBEN, "Terrorismo ou tragicomédia", p. 2. 
Em A insurreição que vem (2013), o Comitê Invisível trata de pensar a insurreição na contemporaneidade. Já no título da obra temos uma referência à ideia de que vem, tal como ela foi utilizada por Agamben em A comunidade que vem (2013). Assim, não se trata da insurreição considerada como um grande evento definido a chegar no futuro (o que se enquadraria no sentido clássico de revolução), mas de algo sempre por vir.

Enquanto no livro de Agamben destaca-se a questão da comunidade em relação com o conceito de désouvrement ${ }^{13}$ conectado ao conceito de inoperosidade ${ }^{14}$, no Comitê Invisível é a insurreição que fica lado a lado com o que vem. Devemos atentar para fato de dois sentidos poderem ser associados à expressão insurreição que vem na obra do grupo francês: se, por um lado, ela significa uma fuga daquilo que existe, por outro ela diz respeito à efervescência de manifestações com característica insurrecionais nas últimas duas décadas, as quais, segundo o grupo, não seriam apenas acontecimentos desvinculados, mas cada um deles, a seu modo, relacionar-se-ia com uma possibilidade de mudança quanto ao funcionamento dos governos e do governo da vida num nível abrangente. Contudo, estes dois sentidos são complementares na medida em que ambos conectam-se. Em $A$ insurreição que vem, com o fortalecimento da potência, com a ideia de como vinculada à forma-de-vida, bem como se conectam com o conceito de potência destituinte, que ganhará destaque nas duas obras seguintes do grupo.

No início da segunda obra do Comitê Invisível, Aos nossos amigos: crise e insurreição (2014), temos uma retomada do segundo sentido de insurreição que vimos acima: "Nós não somos contemporâneos de revoltas esparsas, mas uma única onda mundial de levantes que se comunicam entre si de maneira imperceptível. (...) por mais localizada que seja, toda insurreição emite sinais para além de si própria"15. Este livro dá sequência à primeira publicação, enquanto aquela obra lidava com expectativa pela proliferação de insurreições, esta parte da experiência das inúmeras manifestações políticas com características insurrecionais ocorridas entre a publicação de uma obra e a publicação da outra. O Comitê Invisível aponta também que essas diversas manifestações, que em algum momento pareciam que mudariam muito, foram frustradas na medida em que os manifestantes foram privados da revolução enquanto processo. Seguindo nessa linha, detém-se sobre a relação entre organização e anarquia: "Organizar-se nunca quis dizer se filiar a uma organização. Organizar-se é agir segundo uma percepção comum, em qualquer nível que seja. (...) O que nos falta é uma percepção partilhada da situação"16. A anarquia teria algo de organização somente na medida em que busca compartilhar a percepção de uma situação, não como um modelo de organização. Por isso a ênfase no organizar-se enquanto processo e o Comitê Invisível avaliar como em muitos casos as revoluções fracassaram ao serem privadas do processo revolucionário mesmo. Trata-se, então, de ocupar a potência de organizar-se ao

\footnotetext{
${ }^{13}$ A inoperatividade/inoperância (désouvrement) significa uma ausência de operação e de obra, ou seja, é o inverso de operar. Ela nega uma operatividade, que diz respeito a um pressuposto comum e a uma tarefa ou vocação propriamente humana.

${ }_{14}$ A inoperosidade não é nem obra e nem ausência de obra, mas a obra como uso ao invés de como uma propriedade. Trata-se, então, não de uma ausência de atividade, mas de uma atividade sem propriedade e sem finalidade, que remete à própria possibilidade de obra, ou seja, a uma potência para uso; deste modo, ela deixa a obra em contato com a ausência de obra. Portanto, a inoperosidade difere-se da inoperatividade/inoperância ao dar um emprego à ausência de obra, ao exercitar a potência para uso, restituindo-a às obras: ela deixa a obra em contato com a ausência de obra.

${ }^{15}$ COMITÊ INVISÍVEL, Aos nossos amigos, p. 16.

${ }^{16}$ COMITÊ INVISÍVEL, Aos nossos amigos, p. 19.
} 
invés do poder de governar e de combater o governo enquanto forma ao invés de concentrar o combate em formas específicas de governo, como Estado, Lei, disciplinas etc. ${ }^{17}$

Nessa via, o Comitê Invisível afirma que "o que está em jogo nas insurreições contemporâneas é a questão de saber o que é uma forma desejável de vida e não a natureza das instituições que a subjugam" ${ }^{18}$. Para investigar o que seria uma forma desejável de vida (uma vida vivida como forma-de-vida), o Comitê Invisível lança mão do conceito de potência destituinte, com maior intensidade no capítulo 2.4, intitulado por ele de Teoria da destituição. Há no início deste capítulo uma crítica à ideia de revolução que envolve poder constituído e poder constituinte.

Se as revoluções são sistematicamente traídas, talvez isso seja obra da fatalidade; mas talvez seja o sinal de que há, na nossa ideia de revolução, alguns vícios escondidos que a condenam a esse destino. Um desses vícios reside no fato de ainda pensarmos muito frequentemente a revolução como uma dialética entre poder constituinte e poder constituído. ${ }^{19}$

A partir dessa leitura, o Comitê Invisível pensa a revolução (de cunho insurrecional) como pura destituição, desvinculada, portanto, do círculo vicioso entre constituinte e constituído.

Destituir o poder é privá-lo de seu fundamento. É isso o que justamente uma insurreição faz. [...] Destituir o poder é privá-lo de legitimidade, é conduzilo a assumir sua arbitrariedade, a revelar sua dimensão contingente. [...] $\mathrm{Na}$ insurreição, o poder vigente é mais uma força entre outras sobre um plano de luta comum, e não mais essa metaforça que rege, ordena ou condena todas as potências". (...) Temos de abandonar a ideia de que se faz a revolução em nome de algo. ${ }^{20}$

A destituição lida com um fortalecimento da potência (para o uso, para experiências vividas diretamente), naquele sentido presente no Partido Imaginário e que, de alguma forma, era o conceito de potência destituinte em estágio embrionário. Este fortalecimento visa à participação em uma potência comum (potência para como, para ser enquanto processo, percurso) e constituir uma força que não seja uma organização.

Em Agamben, associado ao conceito de inoperosidade, há um conceito semelhante de potência destituinte. A inoperosidade consiste em uma existência genérica da potência, que não se resume a um trânsito rumo a um fim, mas que se configura, ao invés, como um meio sem fim, de modo que ela sai da lógica da finalidade e da propriedade para a da medialidade. Não se trata de uma ausência de atividade, mas de uma atividade sem propriedade e sem finalidade. A potência para tal atividade é o que Agamben chama de potência destituinte.

\footnotetext{
${ }^{17}$ Cf. COMITÊ INVISÍVEL, Aos nossos amigos, p. 81.

${ }^{18}$ COMITÊ INVISÍVEL, Aos nossos amigos, p. 58.

${ }^{19}$ COMITÉ INVISÍVEL, Aos nossos amigos, p. 87.

${ }^{20}$ COMITÊ INVISÍVEL, Aos nossos amigos, pp. 90-91.
} 
A proximidade entre potência destituinte e o que, no decurso da investigação, denominamos com o termo inoperosidade aqui se mostra com clareza. Em ambas está em questão a capacidade de desativar e tornar algo inoperante um poder, uma função, uma operação humana - sem simplesmente o destruir, mas libertando as potencialidades que nele haviam ficado não atuadas a fim de permitir, dessa maneira, um uso diferente. ${ }^{21}$

A inoperosidade é a dimensão do uso, e a potência destituinte é a possibilidade de levar esse uso ao mundo. Ela pode ser iluminada através da contraposição com a relação entre o poder constituinte e o poder constituído. O poder constituinte é aquele que funda algo (regra, norma, ordem), enquanto o poder constituído é aquele que mantém algo (uma regra, norma ou ordem vigente), recorrendo ao poder constituinte como o seu fundamento. Seguindo a avaliação de Agamben, de modo geral são duas as teses mais comuns sobre a relação entre poder constituinte e poder constituído: uma que defende que o poder constituinte não pode ser condicionado de nenhuma maneira e que ele se mantém externo a todo poder constituído; outra que defende a tese contrária, que reduz o poder constituinte a um poder de revisão previsto no que foi constituído. Ainda que o poder constituinte pareça mais nobre, qualquer uma das duas teses o mantém em relação com o poder constituído. Uma potência destituinte, ao contrário destes, não coloca e nem mantém nada, escapando, portanto, do círculo vicioso entre poder constituinte e poder constituído.

Chamamos de destituinte uma potência capaz de abandonar toda vez as relações ontológico-políticas para que apareça entre seus elementos um contato. O contato não é um ponto de tangência nem um quid ou uma substância em que os dois elementos se comunicam: ele é definido unicamente por uma ausência de representação, só por uma cesura. Onde uma relação é destituída e interrompida, seus elementos estarão em contato, pois é mostrada entre eles a ausência de qualquer relação. Assim, no momento em que uma potência destituinte exibe a nulidade do vínculo que tinha a pretensão de mantê-los juntos, vida nua e poder soberano, anomia e nomos, poder constituinte e poder constituído se mostram em contato sem relação nenhuma; por isso mesmo, o que havia sido cindido de si e capturado na exceção - a vida, a anomia, a potência anárquica - agora aparece em sua forma livre e não provada. ${ }^{22}$

A terceira obra do Comitê Invisível, originalmente intitulada Maintenant e na tradução brasileira intitulada Motim e destituição agora (2017), em grande medida é um aprofundamento do capítulo Teoria da destituição, da obra anterior. Sobretudo no capítulo Destituamos o mundo, quando o grupo reafirma a necessidade de libertar-se dos "fantasmas constituintes", vemos um investimento no conceito de potência destituinte.

21 AGAMBEN, O uso dos corpos, p. 305.

22 AGAMBEN, O uso dos corpos, p. 305. 
Destituere significa, em latim: colocar em pé à parte, erigir isoladamente; abandonar; pôr de lado, deixar cair, suprimir; decepcionar, enganar. Enquanto a lógica constituinte choca-se contra o aparelho de poder sobre o qual ela pensa ter controle, uma potência destituinte se preocupa muito mais em dele escapar, em retirar desse aparelho qualquer controle sobre si, na medida em que agarra o mundo que forma à margem. Seu gesto próprio é $a$ saída, enquanto o gesto constituinte é a tomada de assalto. [...] Ela não se regula por meio dos movimentos do adversário, mas por aquilo que requer aumento de sua própria potência. ${ }^{23}$

Outro ponto a ser observado na terceira obra do Comitê Invisível é o conceito de agora, que dá nome originalmente ao livro Maintenant (Agora) e que podemos relacionar ao conceito de tempo-de-agora em Agamben. Em O tempo que resta (2016), Agamben trata de "entender o sentido e a forma do tempo que ele [Paulo] define como ho nyn kairós, o tempode-agora" ${ }^{24}$. O tempo que leva para acabar é o tempo em que algo é vivenciado; o tempode-agora se relaciona com o como e com o uso na medida em que diz respeito a algo que se finda no mesmo instante em que ocorre: isso é o tempo messiânico, o qual, portanto, já vivemos ou poderíamos viver. Agamben observa que o tempo-de-agora se difere do escatológico e do apocalíptico na medida em que ele não é o fim dos tempos, mas o tempo do fim, isto é, o tempo que resta entre o tempo e o seu fim.

Em O uso dos corpos (2014), Agamben aproxima os conceitos de inoperosidade, potência destituinte e potência anárquica: "em ambos os casos [inoperosidade, potência destituinte e potência anárquica] está em jogo a capacidade de desativar e tornar inoperante, sem simplesmente destruí-lo [um dispositivo ou uma realização específica], mas liberando a sua potencialidade para um uso diverso" 25 . Vinculando a inoperosidade e o pensamento anárquico, ainda em $O$ uso dos corpos, Agamben afirma: “Tanto a tradição anárquica quanto o pensamento do século XX tentaram definir essa potência destituinte sem nunca verdadeiramente conseguir" ${ }^{26}$; isto porque "a anarquia nunca pode estar em posição de princípio: ela pode unicamente se libertar como um contato, lá onde tanto archè como origem quanto archè como comando estão expostos em sua não-relação e são neutralizadas" ${ }^{27}$. Deste modo, aponta-se para uma possibilidade de explorar a potência destituinte da tradição anárquica com recurso ao conceito agambeniano de inoperosidade e de destituição.

Assim, temos que o conceito de potência destituinte figura nas obras do Comitê Invisível de maneira semelhante à que figura nas obras de Agamben, e também que o agora e o tempo-de-agora, em relação com o uso e com a forma-de-vida, mostram-se cruciais para a compreensão da potência destituinte tanto em Agamben quanto no Comitê Invisível. Ao mesmo tempo, tal aproximação, principalmente por meio dos conceitos de destituição e inoperosidade, aponta para uma relação da obra do filósofo italiano com a tradição de pensamento anárquico, conferindo à obra agambeniana uma perspectiva prática de resistência ao governo da vida.

${ }^{23}$ COMITÊ INVISÍVEL, Motim e destituição agora, pp. 94-95.

24 AGAMBEN, O tempo que resta, p. 14.

25 AGAMBEN, O uso dos corpos, p. 305.

${ }^{26}$ AGAMBEN, O uso dos corpos, p. 306.

27 AGAMBEN, O uso dos corpos, p. 307. 


\section{Referências bibliográficas}

AgAmBEN, G. A comunidade que vem. Tradução de Cláudio Oliveira. Belo Horizonte: Autêntica, 2013.

. Autoritratto nello studio. Milan: Nottetempo, 2017a.

. Creazione e anarchia. Vicenza: Neri Pozza, 2017b.

. “O que é um dispositivo?” In: O que é o contemporâneo e outros ensaios. Tradução de Vinícius Honesko. Chapecó: Argos, 2009, pp. 25-54.

O tempo que resta: um comentário à Carta aos Romanos. Tradução de Davi Pessoa. Belo Horizonte: Autêntica, 2016.

O uso dos corpos. Tradução de Selvino J. Assmann. São Paulo: Boitempo, 2017b.

"Terrorismo ou tragicomédia". In: Sopro, 2009. Disponível em: http://culturaebarbarie.org/sopro/n3.pdf. Acesso em: 20/05/2020.

COMITÊ INVISÍVEL. A insurreição que vem. Tradução de Edições Baratas. Brasil: Edições Baratas, 2013.

Aos nossos amigos: crise e insurreição. Tradução Edições Antipáticas. São Paulo: N-1, 2016.

. Motim e destituição agora. Tradução de Vinícius N. Honesko. São Paulo: N-1, 2017.

GUIMARÃES, D. O gesto de anarquia a partir da obra de Giorgio Agamben. 2019. 107 f. Tese (Doutorado em Filosofia Prática) - Universidade Federal da Paraíba, 2019.

JOYCE, James. Ulysses. Tradução de Caetano W. Galindo. São Paulo: Penguin Classics Companhia das Letras, 2012.

PARTI IMAGINAIRE. "Introduction à la guerre civile". In: Tiqqun 2: Zone d'Opacité Offensive. Paris: Parti Imaginaire, 2001, pp. 4-37.

. "Théorie du bloom”. In. Tiqqun 1: Exercices de Métaphysique Critique. Paris:

Parti Imaginaire, 1999, pp. 23-45. 